\title{
PENGELOMPOKKAN DATA MINING PADA JUMLAH PENUMPANG DI BANDARA HANG NADIM
}

\author{
Koko Handoko, Lido Sabda Lesmana \\ Universitas Putera Batam, Indonesia.
}

\section{INFORMASI ARTIKEL}

\section{KATA KUNCI \\ Data Mining, K-Means, Clustering, \\ Data Penumpang}

\section{KORESPONDENSI}

E-mail:

kokohandoko263@gmail.com

\section{Latar Belakang}

Banyaknya data yang dipunyai oleh sebuah bandara penerbangan dapat menyebabkan kesulitan dalam pengklasifikasian data tersebut. Kegiatan pengklasifikasian yang dilakukan oleh manusia masih terbatas, terutama pada kemampuan manusia dalam menampung jumlah data yang ingin diklasifikasikan. Selain itu bisa juga sering terjadi kesalahan dalam pengklasifikasian yang dilakukan atau sering disebut dengan human errors. Penggalian data dari jumlah yang sangat besar ini dapat dilakukan dengan Data Mining.

Data mining adalah proses yang menggunakan teknik statistik, matematika, kecerdasan buatan, dan machine learning untuk mengekstraksi dan mengidentifikasi informasi yang bermanfaat dan pengetahuan yang terkait dari database yang besar. Metode K-means merupakan metode clustering yang paling sederhana dan umum. Hal ini dikarenakan K- means mempunyai kemampuan mengelompokkan data dalam jumlah yang cukup besar dengan waktu komputasi yang relatif cepat dan efisien Namun, metode K-Means memiliki kelemahan yang diakibatkan oleh penentuan pusat awal cluster. (Handoko, 2016).

Clustering merupakan proses mengelompokkan item data ke dalam sejumlah kecil grup sedemikian rupa sehingga masingmasing grup memiliki suatu persamaan antar satu sama lain [2].

Maka daripada itu, tujuan yang akan dicapai pada penelitian ini adalah untuk mengelompokkan data penumpang dalam

pengolahan data yang besar sehingga mendapatkan informasi yang bermanfaat dan pengetahuan yang terkait dari database yang besar. Data yang akan digunakan pada penelitian ini adalah data sampel hasil rekap data penumpang pada bandar udara yang terletak di Batam yaitu Bandar Udara Hang Nadim. 


\section{Kajian Literatur}

\section{A. Knowledge Discovery in Database (KDD)}

Saat ini, konsep Data Mining semakin

dikenal sebagai tools penting dalam manajemen informasi karena jumlahinformasi yang semakin besar jumlahnya. Data Mining sendiri sering disebut sebagai Knowledge Discovery in Database (KDD) adalah kegiatan yang meliputi pengumpulan, pemakaian data historis untuk menemukan keteraturan, pola hubungan dalam set data berukuran besar [1].

Ada beberapa macam pendekatan yang berbeda yang diklasifikasikan sebagai teknik pencarian informasi / pengetahuan dalam KDD. Ada pendekatan kuantitatif, seperti pendekatan probabilistik seperti logika induktif, pencarian pola, dan analisis pohon keputusan.

Pada dasarnya ada enam elemen yang paling esensial dalam teknik pencarian informasi / pengetahuan dalam KDD yaitu:

1. Mengerjakan sejumlah besar data.

2. Diperlukan efesiensi berkaitan dengan volume data.

3. Mengutamakan ketetapan/keakuratan.

4. Membutuhkan pemakaian bahasa tingkat tinggi.

5. Menggunakan beberapa bentuk dari pembelajaran otomatis.

6. Menghasilkan hasil yang menarik.

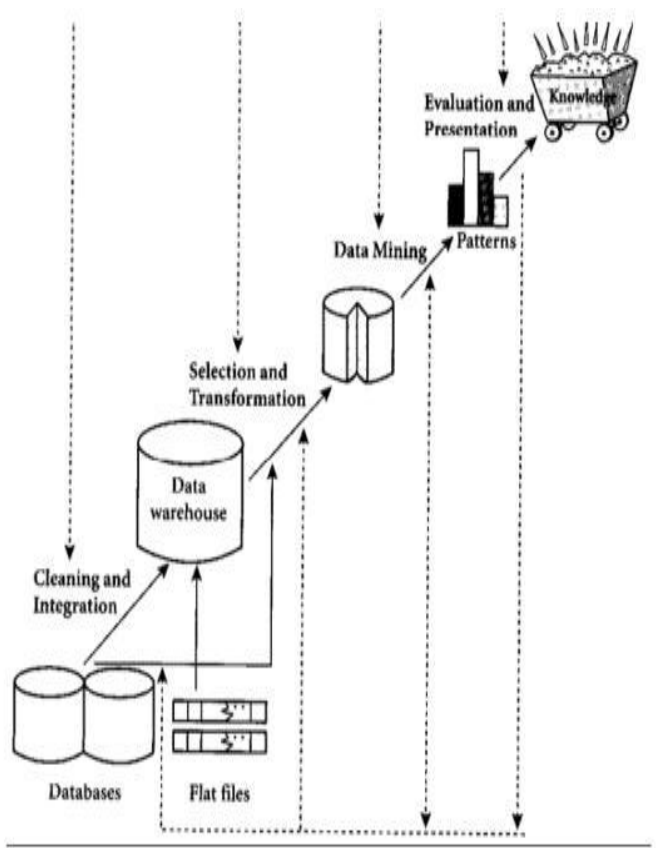

Gambar 1. Tahapan pada KDD

\section{B. Data Mining}

$$
\text { P a g e | }
$$

\section{DataMiningadalahprosesyang}

menggunakan teknik statistik, matematika, kecerdasan buatan, dan machine learning untuk mengekstraksi dan mengidentifikasi informasi yang bermanfaat dan pengetahuan yang terkait dari database yang besar. Data Mining sebenarnya memiliki akar yang panjang dari bidang ilmu seperti kecerdasan buatan (artificial intelligent), machine learning, statistik dan basis data. Beberapa teknik yang sering disebut-sebut dalam literatur data mining antara lain : clustering, classification, association rule mining, neural network, dan genetic algorithm [1].

Data Mining adalah suatu rangkaian proses yang akan menghasilkan keluaran / output berupa sebuah pengetahuan baru yang diharapkan dapat dimanfaatkan di masa depan.

Tahap-tahap pada data mining dapat diilustrasikan seperti berikut : [4]:

1. Pembersihan data (untuk membuang data yang tidak konsisten dan noise)

2. Integrasi data (penggabungan data dari beberapa sumber)

3. Transformasi data (data diubah menjadi bentuk yang sesuai untuk di-mining)

4. Aplikasi teknik DM

5. Evaluasi pola yang ditemukan (untuk menemukan yang menarik/bernilai)

6. Presentasi pengetahuan (dengan teknik visualisasi)

Jika dilihat pada gambar 1 tahapan yang ada pada KDD, dapat dilhat data mining merupakan salah satu tahapan didalamnya. Namun, dalam tahapan data mining, masih terbagi ke dalam beberapa tahapan yang harus dilakukan, yakni sebagai berikut : [5]

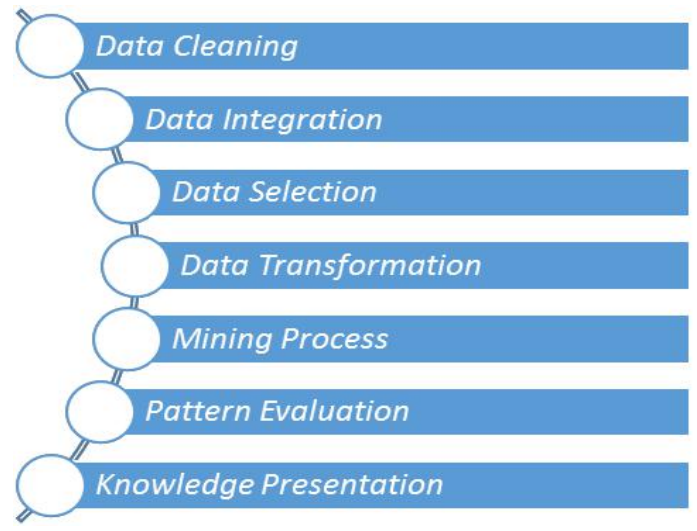

Gambar 2. Tahapan pada Data Mining

- $\quad$ Data Cleaning (Pembersihan Data) 
Data cleaning atau pembersihan data merupakan proses menghilankan data yang tidak relevan dalam sebuah dataset. Data yang tidak relevan seperti data hilang, data tidak valid dan data yang salah ketik akan dibuang agar performasi data mining menjadi lebih ringan karena jumlah yang akan diproses berkurang dan kompleksitas data menjadi lebih gampang.

- $\quad$ Data Integration (Integrasi Data)

Data integration atau integrasi data merupakan hasil persatuan dari beberapa data dari berbagai database yang dimasukkan ke dalam database yang baru. Integrasi harus dilakukan dengan teliti karena kesalahan pada tahap ini dapat menyesatkan dalam pengambilan aksi selanjutnya.

- Data Selection (Seleksi Data)

Data selection atau seleksi data adalah tahap pemiihan data yang akan digunakan karena tidak semua data pada database akan digunakan dalam penelitian. Hanya data yang sesuai dengan kriteria analisis yang akan diambil dari database untuk diteliti.

- Data Transformation (Transformasi Data)

Data transformation atau transformasi data adalah tahap pengubahan format data ke dalam format yang cocok untuk diproses. Beberapa metode data mining membutuhkan jenis format data yang berbeda. Seperti pada clustering, data input harus dalam format data kategorial agar dapat diproses, sehingga pada tahap inilah proses pengubahan format data tersebut dilakukan.

- $\quad$ Mining Process (Proses mining)

Mining process atau proses mining merupakan tahapan proses yang utama. Semua tahapan sebelumnya adalah untuk mendukung tahapan proses ini. Tahapan ini adalah proses menggunakan metode dan algoritma yang ada untuk menemukan pengetahuan dari data yang ada.

- $\quad$ Pattern Evaluation (Evaluasi Pola) Pattern evaluation atau evaluasi pola adalah tahapan dalam mengidentifikasi pola - pola yang ada berdasarkan hasil dari proses mining yang telah dilakukan dan menarik kesimpulan berupa pengetahuan untuk menilai apakah hipotesis yang ada telah terpenuhi atau belum.

- Knowledge Presentation (Presentasi Pengetahuan)

Knowledge presentation atau presentasi pengetahuan adalah tahapan visualisasi atau penyajian hasil pengetahuan yang telah didapat ke dalam deskripsi agar dipahami oleh semua orang.

\section{Pengelompokan Data Mining}

Data Mining dibagi menjadi beberapa kelompok berdasarkan tugas yang dapat dilakukan, yaitu [6]

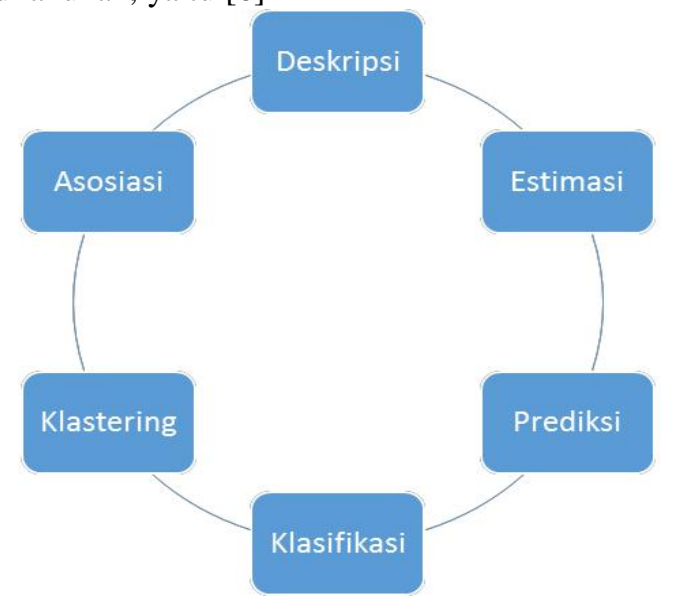

Gambar 3. Pengolompokan Data Mining

- Deskripsi

Deskripsi dari pola dan kecenderungan sering memberikan kemungkinan penjelesan untuk suatu pola atau kecenderungan.

- Estimasi

Estimasi hampir sama dengan klasifikasi, kecuali variabel target estimasi lebih kearah numerik dari pada kearah kategori. Model dibangun menggunakan record lengkap yang menyediakan nilai dari variabel target sebagai prediksi. Selanjutnya, pada peninjauan berikutnya estimasi nilai dari variabel target dibuat berdasarkan nilai variabel predikasi. Sebagai contoh akan dilakukan estimasi tekanan darah sistolik pada pasien rumah sakit 
berdasarkan umur pasien, jenis kelamin, indeks berat badan, dan level sodium darah. Hubungan antara tekanan darah sistolik dan nilai variabel prediksi dalam proses pembelajaran akan menghasilkan model estimasi. Model estimasi yang dihasilkan dapat digunakan untuk kasus baru lainnya.

- Prediksi

Prediksi hampir sama dengan klasifikasi dan estimasi, kecuali bahwa dalam predikasi nilai dari hasik akan ada dimasa mendatang. Beberapa metode dan teknik yang digunakan dalam klasifikasi dan estimasi dapat pula digunakan (untuk keadaan yang tepat) untuk prediksi.

\section{- Klasifikasi}

Dalam klasifikasi, terdapat target variabel kategori. Sebagai contoh

penggolongan pendapatan dapat dipisahkan dalam tiga kategori, yaitu pendapatan tinggi, pendapatan sedang, dan pendapatan rendah.

- Klastering

Pengkluteran merupakan pengelompokan record, pengamatan, atau memperhatikan dan membentuk kelas objek-objek yang memiliki kemiripan. Cluster adalah kumpulan record yang memiliki kemiripan satu dengan yang lainnya dan memiliki ketidakmiripan dengan record-record dalam kluster lain. Pengklusteran berbeda dengan klasifikasi yaitu tidak adanya variabel target dalam pengklusteran. Pengklusteran tidak mencoba untuk melakukan klasifikasi, mengestimasi, atau memprediksi nilai dari variabel target. Akan tetapi, algoritma pengklusteran mencoba untuk melakukan pembagian terhadap keseluruhan data menjadi kelompokkelompok yang memiliki kemiripan (homogeny), yang mana kemiripan dalam satu kelompok akan bernilai maksimal, sedangkan kemiripan dengan record dalam kelompok lain akan bernilai minimal.

\section{- Asosiasi}

Tugas asosiasi dalam Data Mining adalah menemukan attribut yang muncul dalam satu waktu. Dalam dunia bisnis lebih umum disebut analisis keranjang belanja.

\section{K-means Clustering}

Pada penelitian ini, data mining yang dilakukan adalah clustering dengan menggunakan gabungan antara metode K-means dan hierarchical clustering. Dari algoritma hierarchical clustering ini digunakan untuk menentukan pusat cluster. Selanjutnya, pusat cluster yang diperoleh hierarchical clustering tersebut digunakan untuk proses pengelompokan data dengan menggunakan metode $K$-means.

Pada dasarnya clustering merupakan suatu metode untuk mencari dan mengelompokkan data yang memiliki kemiripan karakteriktik (similarity) antara satu data dengan data yang lain. Clustering merupakan salah satu metode Data Mining yang bersifat tanpa arahan

(unsupervised), maksudnya metode ini diterapkan tanpa adanya latihan (training) dan tanpa ada guru (teacher) serta tidak memerlukan target output.

Hierarchical clustering adalah suatu metode pengelompokan data yang dimulai dengan mengelompokkan dua atau lebih objek yang memiliki kesamaan paling dekat. Kemudian proses diteruskan ke objek lain yang memiliki kedekatan kedua. Demikian seterusnya sehingga cluster akan membentuk semacam pohon di mana ada hierarki (tingkatan) yang jelas antar objek, dari yang paling mirip sampai yang paling tidak mirip. Secara logika semua objek pada akhirnya hanya akan membentuk sebuah cluster.

Hierarchical clustering adalah suatu metode pengelompokan data yang dimulai dengan mengelompokkan dua atau lebih objek yang memiliki kesamaan paling dekat. Kemudian proses diteruskan ke objek lain yang memiliki kedekatan kedua. Demikian seterusnya sehingga cluster akan membentuk semacam pohon di mana ada hierarki (tingkatan) yang jelas antar objek, dari yang paling mirip sampai yang paling tidak mirip. Secara logika semua objek pada akhirnya hanya akan membentuk sebuah cluster.

Berikut langkah - langkah agar nilai centroid tidak berubah [7]: 


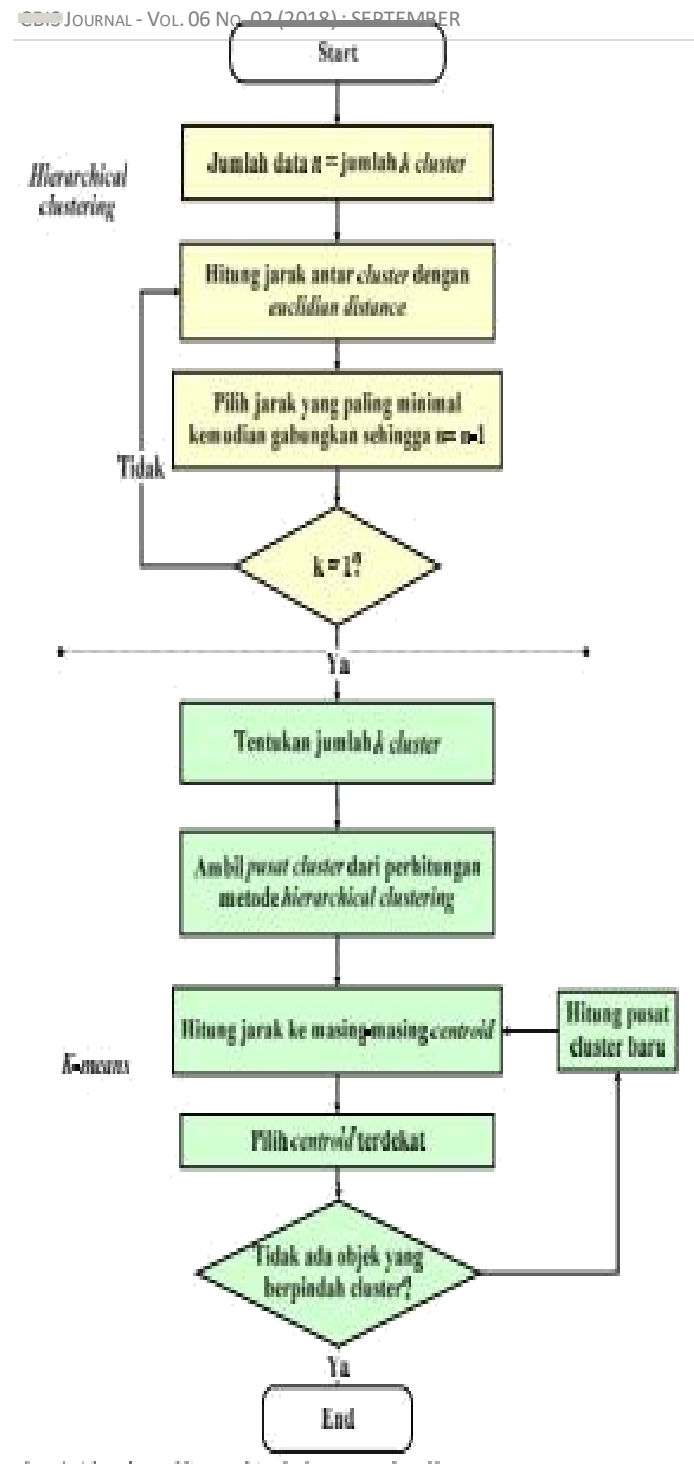

Gambar 4. Langkah mencari nilai centroid

K-Means Clustering merupakan metode yang termasuk ke dalam golongan algoritma Partitioning Clustering. Langkah-langkah dari metode $\mathrm{K}$-Means adalah sebagi berikut:

1. Tentukan $k$ sebagai jumlah cluster yang di bentuk.

Untuk menentukan banyaknya cluster $k$ dilakukan dengan beberapa pertimbangan

seperti pertimbangan teoritis dan konseptual yang mungkin diusulkan untuk menentukan berapa banyak cluster.

2. Bangkitkan $k$ Centroid (titik pusat cluster) awal secara random.

Penentuan centroid awal dilakukan secara random/acak dari objek-objek yang tersedia sebanyak $k$ cluster, kemudian untuk menghitungcentroidclusterke-i berikutnya, digunakan rumus sebagai berikut :

$$
v=\frac{\sum_{i=1}^{n} x_{i}}{n} \quad ; i=1,2,3, \ldots n
$$

3. Hitung jarak setiap objek ke masingmasing centroid dari masing-masing cluster.

Untuk menghitung jarak antara objek dengan centroid penulis menggunakan Euclidian Distance.

$$
d(x, y)=\|x-y\|=\sqrt{\sum_{i=1}^{n}\left(x_{i}-y_{i}\right)^{2}} \quad ; i=1,2,3, \ldots, n
$$

4. Alokasikan masing-masing objek ke dalam centroid yang paling terdekat. Untuk melakukan pengalokasian objek ke dalam masing-masing cluster pada saat iterasi secara umum dapat dilakukan dengan dua cara yaitu dengan hard $k$-means, dimana secara tegas setiap objek dinyatakan sebagai anggota cluster dengan mengukur jarak kedekatan sifatnya terhadap titik pusat cluster tersebut, cara lain dapat dilakukan dengan fuzzy C-Means.

5. Lakukan iterasi, kemudian tentukan posisi centroid baru dengan menggunakan persamaan.

6. Ulangi langkah 3 jika posisi centroid baru tidak sama.

Pengecekan konvergensi dilakukan dengan membandingkan matriks group assignment pada iterasi sebelumnya dengan matrik group assignment pada iterasi yang sedang berjalan. Jika hasilnya sama maka algoritma $k$-means cluster analysis sudah konvergen, tetapi jika berbeda maka belum konvergen sehingga perlu dilakukan iterasi berikutnya.

\section{Metodologi}

Dalam penelitian ini, data yang digunakan adalah hasil rekap data aktifitas lalu lintas penumpang pada Bandar Udara Hang Nadim Batam. Data tersebut terdiri dari data penumpang 
yang datang, penumpang berangkat dan penumpang transit.

\section{A. Variabel}

Dengan menggunakan data tersebut, akan didapatkan variabel penelitian. Variabel penelitian yang digunakan adalah sebagai berikut:

1. Variabel Input

a. Jumlah penumpang yang datang

b. Jumlah penumpang yang berangkat

c. Jumlah penumpang yang transit

2. Variabel Output : Pengelompokan jumlah penumpang

\section{Pembahasan}

\section{A. Analisa Clustering dengan Algoritma K-Means}

K-Means merupakan salah satu dalam metode data mining partitioning clustering yaitu dimana setiap data harus masuk dalam cluster tertentu dan memungkinkan untuk setiap data yang termasuk dalam cluster tertentu melalui suatu tahapan proses, yang pada tahap berikutnya berpindah ke cluster lainnya. K-Means memisahkan data ke $K$ daerah bagian terkenal dan kemudian mampu melalukan klasifikasi data besar dan outlier dengan sangat cepat.

Berikut ini merupakan gambar flowchart dari algoritma K-Means yang digunakan dan menggambarkan langkah - langkah dalam algoritma K-Means dengan anggapan bahwa input adalah jumlah data set sebanyak $n$ data dan jumlah inisialisasi centoid $K=2$ sesuai dengan penelitian.

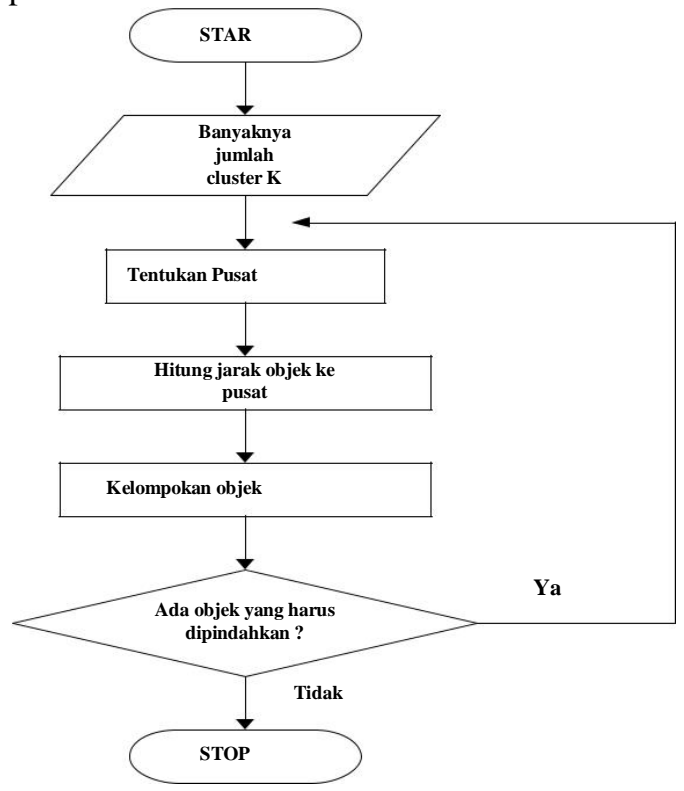

Gambar 5. Flowchart Algoritma K-Means
Penjelaan dari gambar 5 yaitu :

1. Penentuan Jumlah Cluster

Penentuan jumlah cluster berdasarkan data yang kita peroleh akan menjadi langkah pertama dalam melakukan metode algoritma ini.

2. Penentuan Pusat Cluster Awal

Dalam menentukan $n$ buah pusat cluster awal dilakukan pembangkitan bilangan random yang merepresentasikan urutan data input. Pusat awal cluster didapatkan dari data sendiri bukan dengan menentukan titik baru, yaitu dengan merandom pusat awal dari data.

3. Perhitungan Jarak Objek ke Pusat Cluster

Untuk mengukur jarak antara data dengan pusat cluster digunakan Euclidean Distance yaitu algoritma perhiungan jarak data dengan pusat cluster:

1. Ambil nilai data dan nilai pusat cluster

2. Hitung Euclidean Distance data dengan tiap pusat cluster.

4. Pengelompokan Objek Data Jarak hasil perhitungan akan dilakukan perbandingan dan dipilih jarak terdekat antara data dengan pusat cluster, jarak ini menunjukkan bahwa data tersebut berada dalam satu kelompok dengan pusat cluster terdekat.

Adapun algoritma pengelompokan data adalah sebagai berikut :

1. Ambil nilai jarak tiap pusat cluster dengan data.

2. Cari nilai jarak terkecil.

3. Kelompokkan data dengan pusat cluster yang memiliki jarak terkecil.

5. Penentuan Pusat Cluster Baru

Untuk mendapatkan pusat cluster baru bisa dihitung dari rata-rata nilai anggota cluster dan pusat cluster. Pusat cluster yang baru digunakan untuk melakukan iterasi selanjutnya, jika hasil yang didapatkan belum konvergen, proses iterasi akan berhenti jika telah memenuhi maksimum iterasi yang dimasukkan oleh user atau hasil yang dicapai sudah konvergen (pusat cluster baru sama dengan pusat cluster lama).

6. Perhitungan Jarak Pusat Cluster Hitung Euclidean Distance dari semua data ketitik pusat yang baru (C1 dan C2) seperti yang telah dilakukan pada tahap

2. Setelah hasil perhitungan kita 
CBIS J OURNAL - VoL. 06 No. 02 (2018) : SEPTEMBER

dapatkan, kemudian bandingkan hasil tersebut.

\section{B. Tahap Pengolahan Data}

Data yang digunakan dalam penelitian ini adalah data yang bertipe record dengan 36 record. Data yang digunakan dalam penelitian ini adalah data Rekapitulasi Arus Lalu Lintas Angkutan Udara Bandar Udara Hang Nadim Batam. Berikut ini adalah beberapa rekapitulasi data yang diambil :

Tabel 1. Data Rekapitulasi Arus Lalu Lintas Angkutan Udara Bandar Udara Hang Nadim Batam

\begin{tabular}{|l|l|l|l|l|}
\hline $\mathbf{N}$ & & DATAN & BERANGKA & TRANSI \\
\cline { 4 - 5 } & BULAN & G & T & \\
\hline 1 & JAN „15 & 199,703 & 182,996 & 9,137 \\
\hline 2 & FEB „15 & 177,622 & 167,652 & 9,720 \\
\hline 3 & MAR „15 & 186,019 & 174,511 & 9,475 \\
\hline 4 & APR „15 & 187,733 & 176,805 & 12,929 \\
\hline 5 & MEI „15 & 200,033 & 198,265 & 15,229 \\
\hline 6 & JUNI „15 & 192,572 & 200,533 & 16,629 \\
\hline 7 & JULI „15 & 237,443 & 260,933 & 18,154 \\
\hline & AGTS & & & \\
8 &, 15 & 261,001 & 188,385 & 21,583 \\
\hline 9 & SEPT „15 & 179,800 & 168,567 & 12,477 \\
\hline 10 & OKT „15 & 211,832 & 175,035 & 16,799 \\
\hline 11 & NOV „15 & 212,929 & 193,730 & 17,688 \\
\hline 12 & DES „,15 & 266,438 & 260,608 & 19,820 \\
\hline 13 & JAN „16 & 258,573 & 222,315 & 28,320 \\
\hline 14 & FEB „16 & 229,837 & 208,857 & 24,609 \\
\hline 15 & MAR „16 & 247,098 & 216,113 & 34,879 \\
\hline 16 & APR „16 & 232,176 & 214,189 & 23,473 \\
\hline 17 & MEI „16 & 259,825 & 248,723 & 26,459 \\
\hline 18 & JUNI „16 & 198,840 & 238,925 & 19,957 \\
\hline 19 & JULI „16 & 324,215 & 286,773 & 19,741 \\
\hline 20 & AGTS & & & 25,919 \\
\hline 21 & SEPT „16 & 245,484 & 218,048 & 26,138 \\
\hline 22 & OKT „16 & 241,841 & 207,866 & 26,107 \\
\hline 23 & NOV „16 & 243,331 & 220,177 & 34,516 \\
\hline 24 & DES „16 & 290,670 & 274,730 & 33,051 \\
\hline 25 & JAN „17 & 270,214 & 269,101 & 54,937 \\
\hline 26 & FEB „17 & 215,501 & 210,834 & 56,419 \\
\hline 27 & MAR „17 & 241,834 & 240,471 & 68,153 \\
\hline 28 & APR „17 & 227,325 & 238,245 & 56,779 \\
\hline 29 & MEI „17 & 220,896 & 237,202 & 62,176 \\
\hline
\end{tabular}

P a g e | 66

\begin{tabular}{|c|c|c|c|}
\hline 30|JUNI „17 & 196,315 & 250,074 & 44,076 \\
\hline 31JULI „17 & 293,348 & 265,493 & 56,313 \\
\hline \begin{tabular}{l|l} 
& AGTS \\
$32,, 17$ \\
\end{tabular} & 242,978 & 251,641 & 50,258 \\
\hline 33 SEPT „17 & 254,795 & 208,632 & 54,312 \\
\hline 34 OKT „17 & 240,473 & 204,826 & 51,562 \\
\hline 35 NOV „17 & 220,241 & 194,607 & 45,721 \\
\hline 36DES „17 & 257,948 & 234,201 & 38,882 \\
\hline
\end{tabular}

Untuk proses analisa metode K-Means. Seluruh data atribut pada dataset tersebut selanjutnya akan diseleksi untuk mendapatkan atribut-atribut yang bernilai relevan, tidak missing value dan tidak redundance, sehingga data tersebut dapat memenuhi syarat awal yang harus dilakukan dalam data mining, diamana diperoleh dataset yang bersih untuk digunakan pada tahap mining. Atribut pengujian pertama ditentukan sebanyak 3 atribut, yaitu : penumpang berangkat, penumpang datang, dan penumpang transit, sedangkan pada atribut kode diambil dari no-index supaya kita dapat mengetahui no-index mana saja yang diambil menjadi data sampel. Sampel data yang digunakan pada penelitian ini adalah 24 record, yaitu :

Tabel 2. Sampel Rekapitulasi Arus Lalu Lintas Angkutan Udara Bandar Udara Hang Nadim Batam

\begin{tabular}{|l|l|l|l|l|}
\hline $\mathbf{N}$ & & DATAN & BERANGKA & TRANSI \\
\cline { 5 - 5 } & BULAN & G & $\mathbf{T}$ & $\mathbf{T}$ \\
\hline 1 & JAN „17 & 270,214 & 269,101 & 54,937 \\
\hline 2 & FEB „17 & 215,501 & 210,834 & 56,419 \\
\hline 3 & MAR „17 & 241,834 & 240,471 & 68,153 \\
\hline 4 & APR „17 & 227,325 & 238,245 & 56,779 \\
\hline 5 & MEI „17 & 220,896 & 237,202 & 62,176 \\
\hline 6 & JUNI „17 & 196,315 & 250,074 & 44,076 \\
\hline 7 & JULI „17 & 293,348 & 265,493 & 56,313 \\
\hline & AGTS & & & \\
8 &, 17 & 242,978 & 251,641 & 50,258 \\
\hline 9 & SEPT „17 & 254,795 & 208,632 & 54,312 \\
\hline 10 & OKT „17 & 240,473 & 204,826 & 51,562 \\
\hline 11 & NOV „17 & 220,241 & 194,607 & 45,721 \\
\hline 12 & DES „17 & 257,948 & 234,201 & 38,882 \\
\hline 13 & JAN „16 & 258,573 & 222,315 & 28,320 \\
\hline 14 & FEB „16 & 229,837 & 208,857 & 24,609 \\
\hline 15 & MAR „16 247,098 & 216,113 & 34,879 \\
\hline 16 & APR „16 & 232,176 & 214,189 & 23,473 \\
\hline 17 & MEI „16 & 259,825 & 248,723 & 26,459 \\
\hline
\end{tabular}


CBIS J OURNAL - Vol. 06 No. 02 (2018) : SEPTEMBER

\begin{tabular}{|c|l|l|l|l|}
\hline 18 & JUNI „16 & 198,840 & 238,925 & 19,957 \\
\hline 19 & JULI „16 & 324,215 & 286,773 & 19,741 \\
\hline $\begin{array}{l}\text { AGTS } \\
20,16\end{array}$ & 264,791 & 219,815 & 25,919 \\
\hline 21 & SEPT „16 & 245,484 & 218,048 & 26,138 \\
\hline 22 & OKT „16 & 241,841 & 207,866 & 26,107 \\
\hline 23 & NOV „16 & 243,331 & 220,177 & 34,516 \\
\hline 24 & DES „16 & 290,670 & 274,730 & 33,051 \\
\hline
\end{tabular}

\section{a. Analisa Pengelompokan Data}

Dalam menentukan pengelompokan data atau banyaknya jumlah cluster yang akan dibuat, dapat dilakukan dengan beberapa pertimbangan teoritis dan konseptual yang mungkin diusulkan untuk menentukan beberapa banyak cluster yang harus dibentuk. Pada penelitian ini penentuan jumlah kelompok atau cluster ditentukan

berdasarkan pada pengelompokkan data rekapitulasi arus lalu lintas angkutan adara Bandar Udara Hang Nadim Batam. Jadi pada penelitian ini cluster yang akan dibentuk adalah sebanyak tiga kelompok atau nilai $k=3$. Di mana atribut yang digunakan adalah sebanyak 3 buah atribut.

\section{b. Analisa Proses Algoritma K-Means}

Pada tahap ini akan digunakan algoritma $K$ Means untuk mengelompokkan data yang ada. Untuk pengujian pertama, data yang ada akan dikelompokkan menjadi 3 kelompok sebagian yang telah dijelaskan pada sub bab sebelumnya. Adapun prosesnya adalah sebagai berikut :

1. Menentukan jumlah cluster.

Sebagaimana telah dijelaskan pada sub bab sebelumnya bahwa untuk mengelompokkan data pada pengujian yang pertama ini adalah sebanyak 3 cluster, sehingga dapat ditentukan untuk nilai $k$ adalah $k=3$

2. Menentukan titik pusat cluster. Menentukan centroid awal dilakukan secara acak dari data/objek yang tersedia sebanyak jumlah cluster $k$.

3. Hitung jarak setiap data yang ada terhadap setiap pusat cluster.

Untuk menghitung jarak setiap data yang ada terhadap pusat cluster terdapat beberapa cara, yaitu dengan menggunakan

rumus Manhattan/City Block, dan Euclidean Distance. Sedangkan dalam penelitian ini penulis menggunakan rumus Euclidean Distance untuk melakukan
$\mathrm{P}$ a g e

perhitungan jarak setiap data terhadap titik pusat cluster.

4. Alokasikan masing-masing data ke dalam centroid yang paling terdekat.

Dalam mengalokasikan kembali objek ke dalam masing-masing cluster didasarkan pada perbandingan jarak antara data dengan centroid setiap cluster yang ada, objek dialokasikan secara tegas ke dalam cluster yang mempunyai jarak ke centroid terdekat dengan data tersebut.

5. Lakukan iterasi, kemudian tentukan posisi centroid baru dengan cara menghitung rata-rata dari data-data yang berada pada centroid yang sama.

6. Ulangi langkah ke-3 hingga nilai centroid tidak mengalami perubahan.

Untuk dapat membandingkan nilai dari dua iterasi terakhir. Jika nilai dua iterasi terakhir tersebut telah sama, maka proses iterasi telah selesai, dan jika tidak maka ulangi lagi langkah berikutnya.

c. Tahap Hasil Perhitungan

Setelah melakukan langkah-langkah yang telah diuraikan pada sub bab sebelumnya, maka dari data yang ada, akan mendapatkan iterasi terakhir sebagai hasil seperti berikut :
Cluster pertama
$=4$ item
Cluster kedua
$=7$ item
Cluster ketiga
$=13$ item

Dengan hasil perhitungan iterasi terakhir seperti pada tabel di bawah ini :

Tabel 3. Hasil Perhitungan Jarak Dan

Pengelompokan Data Iterasi ke-2

\begin{tabular}{|l|l|l|l|l|l|}
\hline C1 & C2 & C3 & C1 & C2 & C3 \\
\hline 64.294 & 47.111 & 14.930 & 0 & 0 & 1 \\
\hline 93.336 & 40.624 & 20.173 & 0 & 0 & 1 \\
\hline 75.159 & 38.177 & 1.699 & 0 & 0 & 1 \\
\hline 88.239 & 38.423 & 17.424 & 0 & 0 & 1 \\
\hline 45.409 & 47.572 & 35.628 & 0 & 0 & 1 \\
\hline 104.151 & 37.971 & 53.824 & 0 & 1 & 0 \\
\hline 38.617 & 118.723 & 105.991 & 1 & 0 & 0 \\
\hline 63.684 & 54.150 & 20.754 & 0 & 0 & 1 \\
\hline 75.948 & 40.655 & 7.887 & 0 & 0 & 1 \\
\hline
\end{tabular}




\begin{tabular}{|l|l|l|l|l|l|}
82.929 & 44.720 & 12.531 & 0 & 0 & 1 \\
\hline 74.642 & 33.472 & 4.274 & 0 & 0 & 1 \\
\hline 8.910 & 81.123 & 73.234 & 1 & 0 & 0 \\
\hline 28.521 & 58.637 & 61.399 & 1 & 0 & 0 \\
\hline 102.416 & 28.323 & 38.272 & 0 & 1 & 0 \\
\hline 68.176 & 27.375 & 41.821 & 0 & 1 & 0 \\
\hline 77.822 & 8.847 & 36.427 & 0 & 1 & 0 \\
\hline 85.076 & 11.110 & 42.885 & 0 & 1 & 0 \\
\hline 101.219 & 27.871 & 60.556 & 0 & 1 & 0 \\
\hline 17.565 & 77.941 & 71.598 & 1 & 0 & 0 \\
\hline 57.031 & 26.182 & 38.595 & 0 & 1 & 0 \\
\hline 77.707 & 45.373 & 23.711 & 0 & 0 & 1 \\
\hline 88.491 & 38.882 & 21.999 & 0 & 0 & 1 \\
\hline 108.905 & 43.925 & 35.903 & 0 & 0 & 1 \\
\hline 54.172 & 39.573 & 21.754 & 0 & 0 & 1 \\
\hline
\end{tabular}

Daftar Pustaka

\section{Kesimpulan}

Kesimpulan yang dapat diambil pengelompokan data jumlah penumpang pada Bandar Udara Hang Nadim Batam denegan menggunakan data mining clustering metode $K$ means menghasilkan 3 cluster yang dimana data di dalamnya memiliki sifat yang sejenis. Sifat yang sejenis yang dimaksud ada terletak pada rata-rata jumlah penumpang yang ada pada setiap bulannya. Dengan memanfaatkan aplikasi pendukung data mining seperti WEKA, RapidMiner, atau Tanagra, hasil dapat dibuktikan kebenarannya.

\section{Ucapan Terima Kasih}

Pada kesempatan ini, penulis ingin menyampaikan ucapan terimas kasih kepada semua pihak yang telah membantu baik secara langsung ataupun tidak secara langsung dan yang telah memberikan dukungan terhadapa penyusunan penelitian ini.
[1]

[2]

[3]

\section{K. Handoko, "PENERAPAN DATA MINING DALAM \\ MENINGKATKAN MUTU \\ PEMBELAJARAN PADA INSTANSI \\ PERGURUAN TINGGI}

MENGGUNAKAN METODE K-

MEANS CLUSTERING ( STUDI

KASUS DI PROGRAM STUDI TKJ

AKADEMI KOMUNITAS SOLOK

SELATAN )," vol. 2, no. 3, 2016.

R. D. Ramadhani, "Data Mining

Menggunakan Algoritma K-Means

Clustering Untuk Menentukan

Strategi

Promosi,” Ind. Mark. Manag., vol. 1, no. 1, pp. 1-9, 2014.

3] R. R. Putra and C. Wadisman, "IMPLEMENTASI DATA MINING PEMILIHAN PELANGGAN POTENSIAL MENGGUNAKAN ALGORITMA K-MEANS,” vol. 1, no. 1, pp. 72-77, 2018.

[4] F. Y. Bisilisin, Y. Herdiyeni, and B. I. B.

P. Silalahi, "Optimasi K-Means Clustering

Menggunakan Particle Swarm

Optimization pada Sistem Identifikasi

Tumbuhan Obat Berbasis Citra K-Means

Clustering Optimization Using Particle

Swarm Optimization on Image Based

Medicinal Plant Identification System,” vol. 3, no. 2002.

[5] Y. Asriningtias et al., "APLIKASI DATA MINING UNTUK

MENAMPILKAN INFORMASI,” vol.

8, no. 1, pp. 837-848, 2014.

[6] F. Sebagai and I. Enzim,

"Universitas Sumatera Utara," 2014.

[7] T. Rismawan, "APLIKASI K-MEANS UNTUK PENGELOMPOKKAN MAHASISWA,” vol. 2008, no. Snati, 2008. 